\section{What are the Attributes of Sustainable Leadership?}

\author{
Ananda Borgert Armani ${ }^{1}$ \\ Maira Petrini ${ }^{1}$ \\ Ana Clarissa Santos ${ }^{1}$ \\ ${ }^{1}$ PUCRS, Business School, PPGAd, Porto Alegre/Brazil
}

\begin{abstract}
Purpose - The purpose of the study is to provide a more holistic perspective on sustainable leadership (SL), understanding which of its attributes enable changes to more sustainable-oriented organizations and how they are connected.
\end{abstract}

Design/methodology/approach - We carried out an exploratory and qualitative study through multiple and comparative case studies. We selected four organizations and conducted interviews with three different groups of managers in each organization: CSR manager, HR manager, and business managers. In addition, we collected institutional and external documents. We also used observation as a data collection technique. We analyzed the data using the content analysis technique.

Findings - The role of SL changes according to organizational maturity in relation to sustainability. Even the seven attributes recognized as important by all managers (leadership, interpersonal skills, focus on sustainability, orientation toward change, alignment with the organizational culture, values and moral principles, and business vision) showed different positioning depending on the quadrant the managers are a part of.

Originality/value - The proposed framework not only identified what the attributes of SL are but also connected them under two perspectives, pointing out that these attributes are interdependent and interrelated. Our contribution to practice lies in the use of the framework as a guide to lead change in order to bring about a shift to SL in organizations, whether through developing SL programs, or as guidance in the processes of recruiting new leaders.

Keywords - Sustainable Leadership. Attributes. Corporate Social Responsibility. Sustainable Development.
Received on:

08/30/2018

Approved on:

04/29/2020

Responsible Editor:

Prof. Dr. Jesús Barrena

Evaluation process:

Double Blind Review

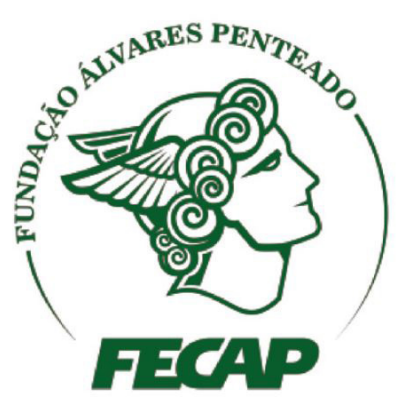

Revista Brasileira de Gestáo de Negócios 


\section{Introduction}

Corporate social responsibility (CSR) can be understood on different levels, such as the institutional, organizational, and individual levels (Aguinis \& Glavas, 2012). On the individual level, the role of leadership is an important factor for the development of CSR actions in organizations, acting as agents of change and levers to create a new vision (Huang, 2013; Nambiar \& Chitty, 2014; Paillé, Chen, Boiral, \& Jin, 2014; Renwick, Redman \& Maguire, 2013). A sustainable organization involves the support and commitment of their leaders, who must implement initiatives to advance towards improving environmental performance (Boiral, Baron, \& Gunnlaugson, 2014). Wiek, Withycombe, and Redman (2011) defend the need to have specific human competencies for sustainability, which can be differentiated from other, more common ones in the organization. In this context, sustainable leaders are professionals who value human development and the environment without neglecting economic aspects. More than that, they reinforce the internal resources of the organization to solve social and environmental challenges, generating value for the business and being responsible for the development of the communities of which they are a part (Voltolini, 2011).

Research has pointed out that personal and organizational values, as well as the personal interest of managers in the subject, contribute considerably to the development of a sustainable leadership profile in organizations (Akrivou \& Bradbury-Huang, 2011; Gardner, Avolio, Luthans, May, \& Walumbwa, 2005). However, dealing with challenges related to sustainability requires specific competencies that can be developed by the individuals inside the organization. The knowledge, skills, and attitudes are related to the (1) individual characteristics from each of the organization's collaborators who engage in sustainable performance (Lans, Blok, \& Wesselink, 2014) and to the (2) business characteristics, such as organizational alignment and the search for sustainability in the strategy (Casserley \& Critchley, 2010; Voltolini, 2012). The development of sustainable competencies runs through fundamental aspects of how the manager views the world and how he/she attributes value to certain organizational behaviors, involving ethical and moral issues (Hind, Wilson, \& Lenssen, 2009; McCann $\&$ Sweet, 2014). The development of awareness among managers can foster their sustainable leadership (Boiral, Baron, \& Gunnlaugson, 2014; Boiral, Cayer, \& Baron,
2009). Although sustainable leadership is a subject of growing interest in academia, the understanding of it still lacks boundaries and a guiding thread. There is a lack of consensus regarding the nomenclature used to define the "requirements" for sustainable leadership. Characteristics, behaviors, competencies, skills, attitudes, and roles are some of these nomenclatures. On the one hand, there is a set of research on the topic which presents a broader view, investigating the organization and presenting sustainable leadership as just another element that leads to corporate sustainability (Hansen, Dunford, Alge, \& Jackson, 2016; Kemp, Nijhoff-Savvaki, Ruitenburg, Trienekens, \& Omta, 2014; Lozano, 2015; Petrini \& Pozzebon, 2010; Ramirez, 2013; Saha, 2014). On the other hand, the research on the topic which presents the characteristics of the sustainable leader (Dentoni, Blok, Lans, \& Wesselink, 2012; Egri \& Herman, 2000; Lans, Blok, \& Wesselink, 2014; Renwick, Redman, \& Maguire, 2013; Saha, 2014; Shrivastava, 1994; Williams \& Turnbull, 2015 ) is carried out in parts, focusing more on only a few characteristics. There is no research that presents it under a comprehensive view. Therefore, this research aims to answer the question: What are the attributes of sustainable leadership? Our main objective is to extend the literature by providing a more holistic perspective on sustainable leadership, understanding what attributes of sustainable leadership enable changes to more sustainable-oriented organizations and how they are connected. Therefore, the specific objective is to identify the attributes that describe sustainable leaderships.

To address this question, we begin with an examination of the literature, looking at different nomenclatures used to characterize sustainable leadership and compiling them under the same label. We adopted the term "attribute" to refer to the description of the elements that characterize sustainable leadership. Then, through an in-depth case study of four organizations, we analyzed the attributes that characterize the sustainable leadership in these firms. The qualitative data was collected from multiple case studies. The data collection included primary data, collected through semi-structured interviews with company managers, and secondary data (documentary research and observation). In each organization, three different groups of managers were interviewed: (1) CSR manager, (2) HR manager, and (3) business managers (support areas or core areas of the organization). The material was analyzed using content analysis. Our contribution through this research is to extend the understanding of the profile of 
sustainable leadership by presenting a framework that combines attributes from both a personal and from an organizational perspective. The organizational perspective is relevant due to its ability to change discourses about sustainability, discouraging its practice. By joining attributes from an organizational perspective with attributes from a personal one, sustainability can be incorporated into the dynamics of the organization more fluidly. In addition, the comparison between organizations at different levels of maturity regarding sustainability practices sheds new light on the attributes of their sustainable leaders. Some attributes clearly have more or less importance due to the maturity of the organization in its adoption of sustainability. Our contribution to practice lies in the use of the framework as a guide to lead change in order to bring about a shift toward sustainable leadership in organizations, whether by developing sustainable leadership programs, or as guidance in the processes of recruiting new leaders.

The article is structured as follows. First, in section 2 , we review the concepts of corporate social responsibility and sustainable leadership. Following this, we consolidate the attributes of sustainable leadership identified in the literature. In section 3 we present the research method and in the section 4 we present the results. In the Discussion section, we propose our attributes of sustainable leadership and, finally, we summarize the article's contributions and suggest possible areas for further research.

\section{Theoretical Background}

\section{I Corporate social responsibility and sustainable leadership}

CSR can be seen as the response of organizations to the challenge of sustainable development, from a perspective that goes beyond short-term profit, focusing on the survival and growth of the business in the long term (McCann \& Sweet, 2014). It therefore concerns a wider view of the organization that goes beyond its financial results or legal obligations, such as ethical and social responsibility, for example (Kramar, 2014). Through the adoption of CSR, companies aim to achieve a balance between economic, social, and environmental aspects of their business practices (Osagie, Wesselink, Blok, Lans, $\&$ Mulder, 2016). Since the first initiatives associated with CSR, its practices have evolved consistently, from a combination of voluntary and disjointed actions to becoming an agenda with different deadlines (Maon,
Lindgreen, \& Swaen, 2009). Organizations have increasingly recognized the importance of their own role in sustainable development by adopting CSR practices. In this context, leaderships play a key role as drivers and motivators of the adoption of sustainability practices in organizations (Kemp et al., 2014; Lozano, 2015; Petrini \& Pozzebon, 2010; Ramirez, 2013; Saha, 2014). The organization's leaders are pivotal for the creation of a culture that promotes shared values, influences the ethical behavior of employees, and enhances the organization's relationship with its stakeholders (McCann \& Sweet, 2014). Therefore, the strategy linked to leadership is a factor that strongly affects the success of organizations' sustainable initiatives (Koednok, 2011). As such, the development of leaders in sustainability is a demand of the environment that organizations are a part of (Brunstein $\&$ Rodrigues, 2014). Hansen et al. (2016) reinforce the importance of the role of sustainable leadership by stating that perceptions of CSR influence employees' opinions about organizational leaders. The review conducted by Hallinger and Suriyankietkaew (2018) analyzed 952 Scopus-indexed documents explicitly concerned with sustainable leadership and pointed out that the subject is emerging as a new domain of study within the field of business administration. These opinions, in turn, affect the perception of an ethical organizational environment. The constant concern about sustainable leadership in sustainable development studies shows the direct responsibility of management within organizations to meet the expectations and values of society (Boiral et al., 2009).

According to Egri and Herman (2000), specific characteristics related to sustainable matters (such as longterm perception, complexity, and multi-disciplinarity) require sustainable leaderships to differ from traditional leaderships. The definition of leadership from a sustainable perspective is based on the idea that organizations are part of an environment in which it is possible to generate sustainable value and revenue for the business. This started along with the definition of sustainability in organizations, but gained space over time (McCann \& Sweet, 2014). Sustainable leaders are professionals who value human development and the environment without neglecting the importance of the financial and structural capital of organizations. In addition, they reinforce the internal resources of the organization to solve social and environmental challenges, generating value for the business and being responsible for the development of the communities they are a part of (Voltolini, 2011). 
Antunes and Franco (2016) complement this concept by asserting that sustainable leadership is characterized by a deep responsibility for the well-being of others, promoting a favorable environment for the development of strength, resilience, and vitality in people. With this, a holistic and integrative view on stakeholders is amplified, highlighting the interpersonal relationships and ethical principles focused on the environment and the community. As a result, organizations and their leaders are, according to the authors, increasingly accountable for what they do and do not do, not only in the eyes of stakeholders, but also society.

Given this context, which highlights the importance of sustainable leadership for the development of CSR and its particularities in relation to traditional leadership, this literature review seeks to identify the aspects that enable these leaders to engage in initiatives related to sustainability. In this search, different nomenclatures were found: "characteristics," "behaviors," "competencies," "skills," "attitudes," and "roles" are some of them. Our goal was not to define them conceptually but to compile them to understand the profile of sustainable leadership. Therefore, in this study, they were grouped together and denominated as "attributes."

\subsection{Attributes of sustainable leadership}

In the organizational context, some leaders are more likely to engage in "responsible behavior" towards sustainable initiatives and activities (Macke \& Genari, 2019; Waldman \& Siegel, 2008). The same authors also state that certain individual characteristics and behaviors of leaders influence their way of implementing CSR initiatives, as well as how they carry out the resulting processes and their success or adjustments. In this sense, a manager's level of consciousness has a strong impact on his/her ability to solve complex situations, and also to make the necessary changes and promote innovation that leads to organizational success (Boiral et al., 2014). Renwick et al. (2013) emphasize the importance of the personal aspects of leaders, such as values and moral principles, in order to run sustainable initiatives in corporations. Sustainable leaderships are guided by a deep appreciation of and identification with nature, which makes their personal values essential in creating sustainable practices (Shrivastava, 1994). Boiral et al. (2009) also emphasize the values focused on environmental measures as important characteristics of these leaders, along with the care they take to meet the expectations of stakeholders and their personal commitment to the organizational transition towards sustainability. In addition, the motivation behind the search for social legitimacy and the achievement of stakeholder expectations is also an important aspect in the study of sustainable leadership (Boiral et al., 2014). Cultural differences, collaborative vision, and constant learning and development can also be part of this sustainable strategy process (Williams \& Turnbull, 2015).

Kurucz, Colbert, Lüdeke-Freund, Upward, and Willard (2017) explore the role of leadership in enabling the impact of strategic sustainability initiatives by describing five practices and capabilities: integrative thinking (increasing the salience of the field and encouraging a holistic perspective), co-production (collaboration in developing principles), dialogic strategic visioning (to identify strategic opportunities), system building focus (understanding actions and strategies in the context of the system of relationships and engaging others), and system quality focus (engaging others to ensure alignment between tools and actions).

The development of sustainable leadership enables the achievement of the expected performance and problem solving related to organizational demands, challenges, and identified opportunities (Osagie et al., 2016), contributing to the creation of a more critical, innovative, and reflexive culture that constantly questions its routines, premises, and principles (Lans et al., 2014). In addition to the ability to recognize sustainable opportunities, it is essential for leaders to demonstrate interpersonal skills that allow them to interact, learn, and adapt to the stakeholders involved (Dentoni et al., 2012).

Williams and Turnbull (2015) also say that nextgeneration leaders need to understand sustainability in its different aspects and at the same time encourage other people in the organization to stick to sustainable practices. In light of this, authors have investigated what needs to be developed in the generation of leaders to come in order to achieve the sustainable objectives of organizations. They have examined four macro fronts: a) expanding the concept of business to a perspective that encompasses the social aspect; b) understanding the role of leadership; c) discussing ethics, injustice, trust, and integrity, and d) understanding cultural differences as part of the path towards a more sustainable world.

Regarding the front related to ethics, injustice, trust, and integrity, the study by Hansen et al. (2016) 
reinforced the importance of the ethical aspect in sustainable leadership, showing that there is a positive correlation between ethical leaders and the attitudes of employees who relate to these leaders. In accordance with these findings, Wu, Kwan, Yim, Chiu, and He (2015) investigated aspects of the ethical leadership of the organization's CEO and concluded that the CEO's ethical behavior enables an ethical culture in the organization as a whole. As a result, employees tend to share these values, directly affecting the CSR aspects of the organization.

Egri and Herman (2000) pointed out other important aspects. Their study indicated that sustainable leaderships are usually change-oriented and strongly concerned about the well-being of others and their environment. Voltolini (2012) describes this concern as a firm belief in the cause of sustainability. Thus, they are able to balance social, environmental, and economic values (Egri \& Herman, 2000), understanding the interdependence between them and realizing that financial results alone do not guarantee the legitimacy of actions (Osagie et al., 2016; Voltolini, 2012). In addition, they have a high need for achievement, involving high levels of affiliation, power, self-confidence, and emotional awareness. All these individual characteristics shape the style of sustainable leaderships, influencing their behavior towards employees and other organizational interactions. Complementing the individual characteristics, Saha (2014) states that sustainable management requires specific knowledge and skills. In order to achieve that, leaders must be trained in terms of: a) establishing sustainable development policies and goals, b) training and delegating tasks to employees, c) developing measures and performance standards, d) designing and executing a deployment plan, e) being transparent, and f) promoting healthy consumption. The demands on sustainable leaders are complex and challenging and therefore leaders need to be able to manage a great number of organizational roles (Egri \& Herman, 2000). In line with the definition of sustainable leadership, Lans et al. (2014) identified the importance of communication, negotiation, collaboration, and empathy, as well as the ability to understand and facilitate cultural diversity among social groups and communities.

As for the Brazilian context, sustainable leaderships have been studied by Brunstein, Scartezini, and Rodrigues (2012) and Todorov, Kniess, and Martins (2013). Brunstein et al. (2012) proposed the concept of societal competence, which can be understood as the capacity to deal with social and environmental impacts in the management of organizations, establishing a dialogue between companies and society, and incorporating the dimensions of power and politics and relations with stakeholders. The study by Todorov et al. (2013) pointed out the importance of communication, understanding indicators aimed at sustainable management, and ethical behavior. Table 1 consolidates the attributes of sustainable leadership identified in the literature, with their respective authors.

Table 1 above was used as the basis for the elaboration of the research instrument, being an initial guide for the field research. In the next section, we detail how the field research was conducted.

\section{Research Method}

We carried out an exploratory and qualitative study through multiple and comparative case studies. We chose the qualitative method because we were interested in capturing and modeling the interviewees meanings regarding the attributes identified in the literature. In addition, a qualitative method gives us the opportunity to search for sustainable practices observed in the field and case study evidence can therefore be seen to contribute new insights (Langley \& Abdallah, 2011). Regarding validity, the method is oriented towards induction and we assume a vision of validity where knowledge is a context-situated construction. Thus, we adopted the credibility criteria, where the "truth" of the findings is viewed through the eyes of those being observed or interviewed and within the context in which the research is carried out (Pozzebon, Rodriguez, \& Petrini, 2014). According to Yin (2005), multiple and comparative case studies involve the logic of replication, which seeks more information to predict similar results. The logic of replication is where different cases are considered for verifying and elaborating theoretical relationships developed from previous cases. Eisenhardt (1989) suggests from four to ten cases because the objective is to abstract from these cases common constructs that can then be used to describe and compare generic process components across all cases. Although the specifics of individual cases make an important contribution to the nature of the constructs induced from the data, it is their common dimensions across cases and not their idiosyncratic features that are emphasized. However, to make this logic work, and to optimize the chances of credible but novel insights, the cases cannot be and are not chosen arbitrarily. Cases are 
Table 1.

Attributes of sustainable leadership

\begin{tabular}{|c|c|}
\hline Attributes & Description \\
\hline $\begin{array}{l}\text { Alignment with } \\
\text { organizational culture }\end{array}$ & Engagement with organizational culture. \\
\hline $\begin{array}{l}\text { Attention to } \\
\text { stakeholders }\end{array}$ & $\begin{array}{l}\text { Focus on and attention paid to meeting stakeh } \\
\text { expectations, involving different audiences. }\end{array}$ \\
\hline $\begin{array}{l}\text { Search for sustainability } \\
\text { in strategy }\end{array}$ & $\begin{array}{l}\text { Expansion of the business concept to the socia } \\
\text { and environmental perspective, introducing } \\
\text { sustainability into organizational strategy. }\end{array}$ \\
\hline $\begin{array}{l}\text { Understanding cultural } \\
\text { diversity }\end{array}$ & $\begin{array}{l}\text { Understanding the cultural diversity of social } \\
\text { groups and the community, promoting } \\
\text { involvement with social matters. }\end{array}$ \\
\hline
\end{tabular}

Specific knowledge Showing specific technical and conceptual skills related to the topic and rules related to sustainability.

Focus on sustainability Personal commitment to sustainability, promoting healthy consumption and recognizing sustainable opportunities.

Interpersonal Skills

Ability to communicate and negotiate, facilitating employee participation and engagement.

Leadership

Change-oriented

Commitment to organizational change, with the ability to convert risks into opportunities.

Identification with sustainable values, concern for the wellbeing of people and their environment.
Playing the role of facilitator and disseminator, with coherence between discourse and practice. principles

Business view
Ability to analyze short-term and long-term needs and impacts, looking to the future.

\section{Authors}

Casserley and Critchley (2010); Voltolini (2011); Al-

Zawahreh, Khasawneh, and Al-Jaradat (2019)

Boiral et al. (2009); Voltolini (2011); Dentoni et al. (2012); Boiral et al. (2014); Al-Zawahreh, Khasawneh, and Al-Jaradat (2019)

Sharma (2000); Egri and Herman (2000); Voltolini (2011, 2012); Wieck et al. (2011); Dentoni et al. (2012); Boiral et al. (2014); Saha (2014); Cosby (2014); Williams and Turnbull (2015); Osagie et al. (2016); Kurucz et al.

\section{(2017)}

Shrivastava (1994); Voltolini (2011); Wiek et al. (2011); Dentoni et al. (2012); Boiral et al. (2014); Lans et al. (2014); Williams and Turnbull (2015); Minelgaite et al. (2019)

Egri and Herman (2000); Voltolini (2011); Renwick et al. (2013); Cosby (2014); Saha (2014); Williams and Turnbull (2015); Osagie et al. (2016); Minelgaite et al. (2019)

Shrivastava (1994); Egri and Herman (2000); Boiral et al. (2009); Voltolini (2012); Renwick et al. (2013);

Boiral et al. (2014); Lans et al. (2014); Saha (2014);

Williams and Turnbull (2015); Kurucz et al. (2017)

Shrivastava (1994); Egri and Herman (2000); Voltolini

(2011, 2012); Wiek et al. (2011); Dentoni et al. (2012);

Todorov et al. (2013); Boiral et al. (2014); Cosby (2014); Lans et al. (2014); Saha (2014); Williams and Turnbull (2015); Osagie et al. (2016); Kurucz et al. (2017)

Egri and Herman (2000); Casserley and Critchley (2010); Voltolini (2011); Todorov et al. (2013); Boiral et al. (2014); Williams and Turnbull (2015); Osagie et al. (2016); Al-Zawahreh, Khasawneh, and Al-Jaradat (2019). Egri and Herman (2000); Boiral et al. (2009); Voltolini (2011, 2012); Dentoni et al. (2012); Boiral et al. (2014); Cosby (2014); Saha (2014); Al-Zawahreh, Khasawneh, and Al-Jaradat (2019).

Shrivastava (1994); Egri and Herman (2000); Boiral et al. (2009); Casserley and Critchley (2010); Voltolini (2011, 2012); Renwick et al. (2013); Todorov et al. (2013); Boiral et al. (2014); Cosby (2014); Nambiar and Chitty (2014); Saha (2014); Choi et al. (2015); Williams and Turnbull (2015); Wu et al. (2015); Hansen et al. (2016) Osagie et al. (2016); Heizmann and Liu (2018)

Shrivastava (1994); Egri and Herman (2000); Voltolini (2011); Wiek et al. (2011); Dentoni et al. (2012); Todorov et al. (2013); Boiral et al. (2014); Cosby (2014); Saha (2014); Wu et al. (2015); Osagie et al. (2016); AlZawahreh, Khasawneh, and Al-Jaradat (2019). also carefully selected to represent what Pettigrew (1990) labeled "polar types," thus emphasizing comparisons between extremes and, in our case, the different levels of adoption of sustainability and the time in which the organizations develop sustainability practices, where the sharpness of contrasts is clearly helpful in enhancing the clarity of insights. Taking this into account, the choice of the cases sought to meet two criteria: (1) being listed (or not) in the Bovespa Corporate Sustainability Index (ISE) in 2016 and (2) different lengths of time in the index. In the Brazilian context, the ISE plays the same role as the Dow Jones Sustainability Index (DJSI) does 
in the world. Table 2 explains the cross-referencing of the company selection criteria. We selected four companies, each one representing a quadrant, thus aiming to provide possible comparisons between the different companies participating in the study.

The data collection included primary data, collected through semi-structured interviews, and secondary data (documentary research and observation), allowing triangulation of the data (Yin, 2005). The interview script was drawn from the attributes previously identified in the literature (Table 1). It was organized into three parts: the first one involved company characterization, the second involved the respondent's characterization, and the last one involved attribute questions, with two questions designed to evaluate each attribute based on the definition of what the attribute refers to. Other specific questions could arise during the interview. In each organization, three different groups of managers were interviewed: (1) CSR manager, (2) HR manager, and (3) business managers (support areas or core areas of the organization that are not directly related to CSR). As criteria for selecting the respondents, we decided to interview managers who had been in the company for at least two years. By doing so, it was possible to obtain different profiles of managers in the same organization (Table 3), making the analyses more consistent. All the interviews occurred individually over a period of three months. In addition, we analyzed documents of the organizations (informative and website) and documents made available by the managers interviewed, such as sustainable index controls, CSR practice disclosure materials, and internal materials related to CSR projects. We also analyzed formal documents regarding CSR practices in the organizations, such as the Social Report, GRI (Global Reporting Initiative), and GIFE (Group of Institutes, Foundations, and Companies). The aim of the document analysis was to obtain more information about the organizational characteristics and the adopted CSR practices. Finally, observation was also used as a

Table 2.

Company selection criteria

\begin{tabular}{lll}
\hline & \multicolumn{1}{c}{ Companies listed in ISE in 2016 } & \multicolumn{1}{c}{ Companies not listed in ISE in 2016 } \\
\hline Permanence time & Quadrant 1 - IND1 & Quadrant 3 - IND2 \\
& In ISE for more than 6 consecutive years & In ISE for at least 5 years and left in 2016 \\
Quadrant 2 - SERV1 & Quadrant 4 - SERV2 \\
In ISE for no longer than 3 years & Has never been in ISE \\
\hline
\end{tabular}

Table 3.

\section{Interviewee Profile}

\begin{tabular}{|c|c|c|c|c|c|c|c|}
\hline Interviewee & Age (years) & Gender & $\begin{array}{c}\text { Time at } \\
\text { Company } \\
\text { (years) }\end{array}$ & Company & $\begin{array}{l}\text { Company } \\
\text { Quadrant }\end{array}$ & Area & $\begin{array}{l}\text { Time of } \\
\text { Interview }\end{array}$ \\
\hline E1 & 35 & $\mathrm{~F}$ & 4 & IND 1 & 1 & CSR & $45 \mathrm{~min}$ \\
\hline E2 & 40 & $\mathrm{~F}$ & 7 & IND 1 & 1 & HR & $40 \mathrm{~min}$ \\
\hline E3 & 42 & M & 15 & IND 1 & 1 & Operations & $60 \mathrm{~min}$ \\
\hline E4 & 58 & $\mathrm{~F}$ & 30 & SERV1 & 2 & CSR & $45 \mathrm{~min}$ \\
\hline E5 & 36 & F & 4 & SERV1 & 2 & HR & $30 \mathrm{~min}$ \\
\hline E6 & 34 & F & 5 & SERV1 & 2 & Operations & $45 \mathrm{~min}$ \\
\hline E7 & 40 & $\mathrm{~F}$ & 20 & SERV1 & 2 & Operations & $80 \mathrm{~min}$ \\
\hline E8 & 25 & $\mathrm{~F}$ & 4 & IND 2 & 3 & CSR & $90 \mathrm{~min}$ \\
\hline E9 & 52 & $\mathrm{~F}$ & 31 & IND 2 & 3 & HR & $30 \mathrm{~min}$ \\
\hline E10 & 53 & M & 22 & IND 2 & 3 & Operations & $45 \mathrm{~min}$ \\
\hline E11 & 32 & M & 6 & IND 2 & 3 & Operations & $45 \mathrm{~min}$ \\
\hline E12 & 32 & $\mathrm{~F}$ & 2 & SERV2 & 4 & HR & $40 \mathrm{~min}$ \\
\hline E13 & 36 & M & 6 & SERV2 & 4 & Operations & $80 \mathrm{~min}$ \\
\hline E14 & 32 & M & 3 & SERV2 & 4 & Operations & $40 \mathrm{~min}$ \\
\hline
\end{tabular}


data collection technique. Here, a script was established, in which the observations made at the interview sites, related to the physical structure and forms of internal communication, were taken into account.

The data were analyzed using the content analysis technique (Bardin, 2009). After transcribing the interviews, the reports were included in NVIVO11. The initial categories were the attributes identified in the literature. From these categories we derived the subcategories, identified from the information that emerged from the field research. Finally, a comparative analysis was carried out considering the four quadrants related to ISE 2016, seeking to identify similarities and differences between the managers interviewed.

\section{Results}

The attributes raised in the literature were analyzed according to their importance identified in the reports from the interviews. In order to carry out this study, we considered it to be important how much each attribute appears in the manager's practice through his/her speech, considering not only the number of statements related to each attribute, but also their intensity. Table 4 summarizes the analysis of the attributes according to quadrants. The attributes are displayed in descending order according to their importance as identified in the reports from the interviews.

Among the eleven attributes previously identified in the literature, seven of them were important for all the interviewees: 1) leadership, 2) interpersonal skills, 3) focus on sustainability, 4) orientation towards change, 5) alignment with the organizational culture, 6) values and moral principles, and 7) business vision. For this research, we considered it to be important how much the attribute is present in the respondent's practice through his/her speech, considering not only the number of statements related to the attribute, but also the intensity of the narrative regarding the attribute. Additionally, the low importance of some attributes is reinforced by their absence in the organizations.

Leadership was highlighted in the speech of all the interviewees. The managers demonstrated a strong understanding of their role as leaders, acting as facilitators of sustainable initiatives. There were many reports about the importance of the manager's participation and his/ her role as a model when it comes to sustainable actions. Interviewee E4 stated that "the leader is usually the mirror. They're a reference that people admire and want to

Table 4.

Summary chart of attribute analysis by quadrants

\begin{tabular}{|c|c|c|c|c|}
\hline Attribute & Quadrant 1 & Quadrant 2 & Quadrant 3 & Quadrant 4 \\
\hline Leadership & $\begin{array}{l}\text { Role model manager and } \\
\text { facilitator }\end{array}$ & $\begin{array}{l}\text { Role model manager and } \\
\text { facilitator }\end{array}$ & $\begin{array}{l}\text { Role model manager and } \\
\text { facilitator }\end{array}$ & Role model manager \\
\hline Interpersonal Skills & $\begin{array}{l}\text { Organizational } \\
\text { communication }\end{array}$ & $\begin{array}{l}\text { Manager-centered } \\
\text { communication }\end{array}$ & $\begin{array}{l}\text { Manager-centered } \\
\text { communication }\end{array}$ & $\begin{array}{l}\text { Manager-centered } \\
\text { communication }\end{array}$ \\
\hline Focus on Sustainability & Sustainability focused & Sustainability focused & Sustainability focused & Sustainability focused \\
\hline Change-Oriented & $\begin{array}{l}\text { Actions to overcome } \\
\text { challenges }\end{array}$ & $\begin{array}{l}\text { Actions to overcome } \\
\text { challenges }\end{array}$ & $\begin{array}{l}\text { Actions to overcome } \\
\text { challenges }\end{array}$ & $\begin{array}{l}\text { Actions to overcome } \\
\text { challenges }\end{array}$ \\
\hline $\begin{array}{l}\text { Alignment with } \\
\text { Organizational Culture }\end{array}$ & $\begin{array}{l}\text { Identification with } \\
\text { culture }\end{array}$ & $\begin{array}{l}\text { Identification with } \\
\text { culture }\end{array}$ & $\begin{array}{l}\text { Identification with } \\
\text { culture }\end{array}$ & $\begin{array}{l}\text { Difficulty identifying } \\
\text { with culture }\end{array}$ \\
\hline $\begin{array}{l}\text { Values and Moral } \\
\text { Principles }\end{array}$ & Active personal practices & Active personal practices & Active personal practices & $\begin{array}{l}\text { Discontinued personal } \\
\text { practices }\end{array}$ \\
\hline Business Vision & $\begin{array}{l}\text { Long-term management } \\
\text { and indicators }\end{array}$ & $\begin{array}{l}\text { Short-term management } \\
\text { and indicators }\end{array}$ & $\begin{array}{l}\text { Short-term management } \\
\text { and indicators }\end{array}$ & Short-term management \\
\hline $\begin{array}{l}\text { Attention to } \\
\text { Stakeholders }\end{array}$ & $\begin{array}{l}\text { Collaborators and } \\
\text { community }\end{array}$ & $\begin{array}{l}\text { Collaborators, } \\
\text { Community, } \\
\text { Stakeholders, customers, } \\
\text { and suppliers }\end{array}$ & $\begin{array}{l}\text { Collaborators and } \\
\text { community }\end{array}$ & Community \\
\hline $\begin{array}{l}\text { Search for Sustainability } \\
\text { in Strategy }\end{array}$ & Influencers & Facilitators & Facilitators & Absent \\
\hline Specific Knowledge & Focus on attitude & Knowledge matters & Focus on attitude & Focus on attitude \\
\hline Understanding Diversity & $\begin{array}{l}\text { Actions contemplating } \\
\text { diversity }\end{array}$ & $\begin{array}{l}\text { Social actions for } \\
\text { communities in general }\end{array}$ & $\begin{array}{l}\text { Social actions for } \\
\text { communities in general }\end{array}$ & $\begin{array}{l}\text { Social actions for } \\
\text { communities in general }\end{array}$ \\
\hline
\end{tabular}


follow. And that makes people participate." Additionally, interviewee E9 pointed out that "the leader needs to have influence, be an inspiring leader, who does, who sets an example and leads others to understand the importance and difference we make in our world with small actions."

Interpersonal skills meant the role of the manager as the agent for the engagement of teams through the dissemination of concepts (quadrants 2, 3, and 4). In the organization of quadrant 1 , the managers explained their transference of this role to the internal communication area, being the ones in charge of accomplishing this engagement. They pointed out the different means of communication used by their company and the large amount of information made available to collaborators, but did not mention their role as disseminators of sustainable initiatives proposed by their organization since there is a specific area in charge of this communication so that it aligned with their company as a whole. Even so, they emphasize the importance of the attribute and that a great deal of organizations essentially depend on the manager to communicate the sustainability actions. Interviewee E7 stated that "we have weekly management ritual care units, where the coordination meets with the entire team to share important information. And in those moments, we also share information about actions, campaigns, opportunities, or messages that we need to reinforce."

Focus on sustainability deals with the value given to sustainable practices as part of the activities of the manager in the organizational context. All the managers provided evidence about organizational actions focused on social, environmental, and sustainable development, highlighting the positive impacts that this generates both on society and on the people who are part of the organization. Interviewee E8 stated that "we have a lot of focus on education and management. So, these projects are a priority within our requirements. Education and management can positively transform the world in some way. So, since we can't embrace everything, we focus on these two things." Even the managers in quadrant 4, whose organization factually embraces sustainable practices, reinforce their importance.

Orientation towards change appeared in the managers' reports on the challenges they encountered and actions taken to overcome these, thus acting as agents of change. This attribute comes up in the creative solutions narrated by the managers in order to maintain sustainability initiatives even in periods of greater pressure for financial results: "the biggest challenge is getting people to move in the same direction. This is a big challenge; there is always someone in the company who doesn't want to collaborate" (interviewee E4). The company managers of the first three quadrants mentioned this.

Alignment with the organizational culture. Managers understand sustainability as being part of the culture of the organization they work for, belonging to it and identifying with it. The managers in quadrant 4 , on the other hand, had difficulties embracing the culture of their organization as their company did not have a sustainability-oriented culture. Precisely because they demonstrate the attributes of leadership and values and moral principles, the managers lack this alignment with their organizational culture, thus reinforcing the importance of this attribute.

We have had this awareness here for many years. It's part of the company: a culture of respect and actions focused on the environment, actions for sustainability. We've intensified it more in recent years. I think the leaders of the company are different. They're different when engaging in the campaigns that the company promotes; they push forward. (Interviewee E2)

Values and moral principles refer exclusively to the individual scope, involving ethical aspects and personal practices, which are independent of the organization. The managers from quadrants 1, 2, and 3 reported numerous examples of sustainable actions practiced by themselves in their personal life and the relationship between these practices and the organizational context. Interviewee E4 stated that "the person feels good knowing that the company has ethics, because all this is sustainability. In fact, this is a cause for pride, working in a company that has the social concern, that respects diversity." On the other hand, the quadrant 4 managers reported that they had practices, but ended up leaving them aside.

Business vision is seen as important for the managers of the companies from quadrants 1,2 , and 3 , but only the managers of quadrant 1 (longer time listed in the ISE) provided evidence of long-term management. All the managers in the first three quadrants know and follow the management of the sustainable indicators of their companies and their own areas. The managers in quadrant 4 reported they have a more short-term perspective and lack management indicators, thus discouraging them from taking CSR actions. The documents corroborate the findings for this attribute. The company from quadrant 1 has official indicators and information about the long- 
term sustainability strategy on its website. The companies from quadrants 2 and 3 have less information on their websites, but the managers interviewed sent some materials with indicators and other information to be analyzed. The company from quadrant 4 , on the other hand, did not provide information on indicators and sustainable strategy, which are not present on its website.

The four remaining attributes, (1) attention to stakeholders, (2) search for sustainability in the strategy, (3) specific knowledge, and (4) understanding cultural diversity, mattered differently to the managers. Attention to stakeholders and specific knowledge were only highlighted by the managers in quadrant 2 , whose organization recently joined the ISE. Since it is still consolidating its sustainability, the organization has been focusing strongly on the dissemination of sustainable initiatives to different stakeholders and understands the importance of having specific knowledge, as managers are references to their teams and need to direct their actions with more in-depth and technical information. The last two attributes - search for sustainability in the strategy and understanding cultural diversity - only had value for the managers in quadrant 1 , the longest listed organization in the ISE. Regarding the search for sustainability in strategy, the managers highlighted their role as influencers of sustainability strategies for the highest hierarchical levels of their companies. The managers in quadrants 2 and 3 notice the sustainability vision of their organization but understand their role as being only facilitators of this process with their subordinates, and not as influencers of the top management. Understanding cultural diversity for the managers in quadrants 2 and 3 is about social actions involving NGOs, institutions, and communities in general, without actually understanding the concept of cultural diversity. This result reinforces the relationship between sustainability maturity and the role of sustainable leadership as discussed in the next section.

\section{Discussion}

Our results show that the role of sustainable leadership changes according to organizational maturity in relation to sustainability. Even the seven attributes recognized as important by all managers showed different positioning depending on the quadrant the managers are a part of. Communication as an engagement tool, the main characteristic of interpersonal skills, is recognized as important by the managers in quadrant 1 . However, this communication is carried out by structures and areas in the organization specifically focused on it. This occurs because the company in quadrant 1 , long listed in the ISE, presents more mature CSR practices, having developed in its organizational structure actors responsible for internal and external communication strategies. The different positioning in another three attributes also evidences a greater maturity in relation to sustainable practices: business vision, search for sustainability in the strategy, and understanding cultural diversity. Aspects such as long-term vision, management of indicators, manager as an influencer of sustainability in the strategy, and concern for actions that contemplate diversity, are mandatory for several types of sustainable certifications, and this explains their evidence in this organization. In the search for sustainability in the strategy, the role of the sustainable leadership seems to float on a continuum of total absence, passing through facilitators of the strategy for receivers, to influencers of the strategy with the senior management, giving voice to collaborators. The managers of quadrant 4 reported they did not see sustainability in their organization's strategy and were even confused about this attribute, demonstrating that they end up neither playing the role of influencers nor facilitators in sustainability strategy, since it does not exist. Therefore, the organization in quadrant 4 reinforced the importance of some attributes when pointing out how much the non-existence of them inhibits sustainable development practices. The managers viewed attributes such as alignment with the organizational culture, values and moral principles, and business vision as important, but non-existent.

As we dug deeper into understanding each attribute, we realized that the boundaries between them were unclear. Leadership and interpersonal skills were strongly related, since both talk about the role of the manager in raising awareness of sustainable initiatives. Leadership involves the idea that leaders need to be facilitators of sustainability, practicing empathy, being an example of change, and having coherence between discourse and practice (Hansen et al., 2016; Williams \& Turnbull, 2015). Interpersonal skills refers to the ability to motivate, engage, and facilitate collaborative team participation in sustainable actions (Wiek et al., 2011). Our research clearly points out that leadership translates into an example or model and interpersonal skills into communication. Whether through example or communication, these two attributes can be converted 
into a single one that concerns the role of managers in employee engagement in, moving, sustaining, and disseminating sustainability. According to Paillé et al. (2014) and Macke and Genari (2019), when managers believe in the importance of sustainable initiatives, they lead and act as facilitators of the strategy implementation process with their collaborators. We believe these two attributes can go under just one label: "ability to engage." Therefore, the ability to engage attribute describes a leader that becomes a role model through his/her actions and communication, creating a ripple effect that influences the behavior of those around him/her. This definition is reinforced by Ketola (2010), who points out that individuals boost or repress responsible behavior: inspiring leaders pull others to higher ethical levels of behavior.

Values and moral principles are also linked to two other attributes: focus on sustainability and alignment with the organizational culture. Sustainable leaderships value and identify with environmental actions, which makes their personal values fundamental when conducting sustainable practices (Boiral et al., 2009; Shrivastava, 1994). Lans et al. (2014) state that these leaders are focused on sustainable initiatives, which can lead to the identification and expansion of opportunities related to sustainable development. However, when the organization does not present a sustainability-oriented culture, managers whose individual attributes lead to sustainability resent the absence of a sustainable culture. Similarly, there is a relationship between focus on sustainability and values and moral principles: sustainable actions directed by the organization reinforce individual actions, and their non-existence negatively affects those individual actions. In short, these three attributes affect each other directly and are at the intersection between two perspectives of sustainable leadership attributes: the personal perspective and the organizational perspective. The perspectives differ according to the origin of each attribute, whether individual or organizational. At the intersection, there are attributes that influence each other, whether they have individual or organizational roots. Figure 1 displays a framework of sustainable leadership attributes in these perspectives, highlighting the six attributes identified as being important by all organizations.

On one hand, the organizational perspective links attributes whose roots relate to the organization of which the manager is a part, such as business vision, search for sustainability in strategy, attention to stakeholders, and understanding cultural diversity. We note that only one attribute of this perspective matters to all the organizations. The other attributes were only identified in the organizations with the highest level of maturity, and even in these, they occur with different positioning. On the other hand, the personal perspective contains attributes considered to be important by all, one of them being the convergence of two attributes identified in the literature. Renwick et al. (2013) stress the importance of leaders' personal aspects,

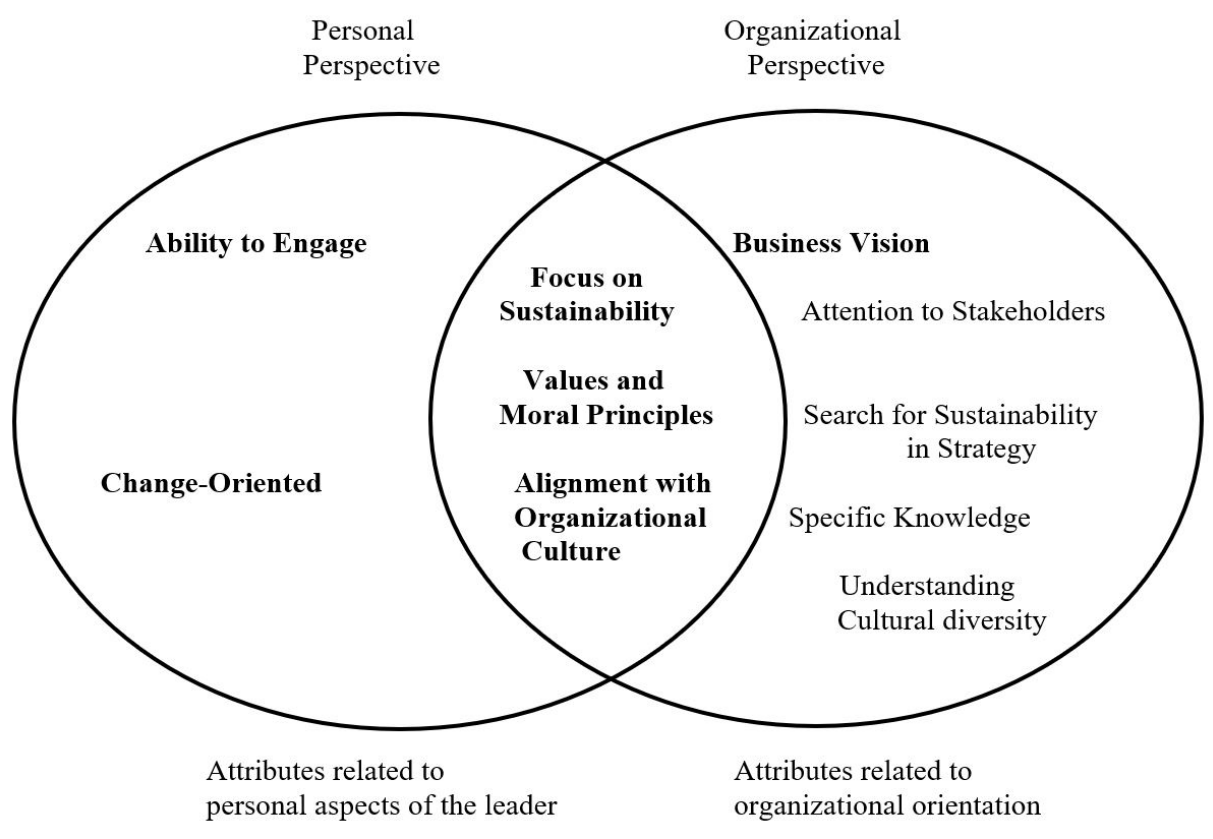

Figure 1. Attributes of Sustainable Leadership in Perspectives 
such as values and moral principles, for engagement in sustainable corporate initiatives. At the same time, working for a socially responsible organization can raise levels of organizational identification, engagement, retention, sense of belonging, and commitment (Aguinis \& Glavas, 2012). Establishing a connection between individual and collective values can build an important foundation for organizations to consolidate sustainability in their practices at any corporate level (Nambiar \& Chitty, 2014). In this sense, we can see attributes at the intersection between the perspectives. These attributes relate both to the manager's personal aspects and to the organizational context and mutually influence each other. Regarding moral values and principles, the leaders in quadrant 4 reported that they had previously had sustainable practices but ended up not using them. Some of these leaders linked their personal practices to the initiatives practiced by their previous organizations, which shows how the practice in the organization can influence the performance and continuity of leaders' personal practices. Egri and Herman (2000) argue that sustainable leaders need to balance their personal values with their organizational ones, so that the decisions made rely on strategies that reconcile sustainable values and principles with traditional organizational values and principles. Recently, Osagie et al. (2016) corroborated this balance between personal ethical values and organizational goals as an important competence of sustainable leaderships.

\section{Conclusions}

This research aimed to understand the attributes that characterize the profile of sustainable leaderships. When a company initiates CSR practices, its leadership plays a fundamental role in the implementation and dissemination of the CSR practices. For this, some attributes are important and different in relation to leadership in other contexts. From the literature review, we identified 11 attributes that characterize sustainable leadership in organizations. We then analyzed the importance of these attributes for managers of different organizations, identifying similarities and differences between them. Among the 11 attributes previously identified in the literature, seven of them were important for all the interviewees. In our framework, we proposed a new way to look at the attributes. First, we redefined two attributes into one. The "ability to engage" attribute describes a leaders that is a role model through his/her actions and communication, creating a ripple effect that influences the behavior of those around him/her. This attribute is a combination of leadership and interpersonal skills. Second, we connected the attributes and place in perspectives. Finally, we identified the attributes that are at the intersection between the perspectives.

Our main contribution, the proposed framework, not only identified what the attributes of sustainable leadership are, but also connected them in two perspectives, pointing out that such attributes are interdependent and interrelated. The organizational perspective is relevant in its ability to change discourses about sustainability, discouraging its practice. By joining attributes from an organizational perspective with those from a personal perspective, sustainability is incorporated into the dynamics of the organization more fluidly. Additionally, we point out that the organization's maturity in relation to the adoption of sustainability causes some attributes to take different positioning. Some attributes are more important than others depending on the level of sustainability maturity, evidencing that sustainable leadership attributes need to be dynamic given the context of the organization. Our contribution to practice lies in the use of the framework as a guide to lead change in order to bring about a shift to sustainable leadership in organizations, whether by developing sustainable leadership programs, or as guidance in the processes of recruiting new leaders.

Some analyses lead us to believe that the attributes of sustainable leadership also differ according to the leader's area of performance inside the organization. Four attributes, a) attention to stakeholders, b) search for sustainability in strategy, c) specific knowledge, and d) understanding cultural diversity, did not always have the same level of importance among the leaders in the different quadrants, but there was consensus among one group: CSR leadership. These managers step up in their organizations' sustainable initiatives, experiencing more intensively the different aspects related to these actions and reinforcing the difference from common leadership. This result can be studied in depth in future research, as well as understanding if attributes change according to organizational levels. Our research focused on the perception of managers and could be expanded by including the perception of their collaborators and c-level in order to identify evidence of the attributes studied, as well as divergences between the reports. 


\section{References}

Aguinis, H., \& Glavas, A. (2012). What we know and don't know about corporate social responsibility: A review and research agenda. Journal of management, 38(4), 932-968.

Akrivou, K., \& Bradbury-Huang, H. (2011). Executive catalysts: Predicting sustainable organizational performance amid complex demands. The Leadership Quarterly, 22(5), 995-1009.

Al-Zawahreh, A., Khasawneh, S., \& Al-Jaradat, M. (2019). Green management practices in higher education: The status of sustainable leadership. Tertiary Education and Management, 25(1), 53-63.

Antunes, A., \& Franco, M. (2016). How people in organizations make sense of responsible leadership practices: Multiple case studies. Leadership \& Organization Development Journal, 37(1), 126-152.

Bardin, L. (2009). Análise de conteúdo. Lisboa: Edições 70.

Boiral, O., Baron, C., \& Gunnlaugson, O. (2014). Environmental leadership and consciousness development: A case study among Canadian SMEs. Journal of Business Ethics, 123(3), 363-383.

Boiral, O., Cayer, M., \& Baron, C. M. (2009). The action logics of environmental leadership: A developmental perspective. Journal of business ethics, 85(4), 479-499.

Brunstein, J., Scartezini, V. N., \& Rodrigues, A. L. (2012). Sustentabilidade na educação corporativa e o desenvolvimento de competências societais. Organizaçóes \& Sociedade, 19(63).

Brunstein, J., \& Rodrigues, A. L. (2014). Gestores e sustentabilidade: A difícil tradução do significado para a ação competente. Revista Alcance, 21(1), 05-24.

Casserley, T., \& Critchley, B. (2010). A new paradigm of leadership development. Industrial and Commercial Training, 42(6), 287-295.

Choi, S. B., Ullah, S. M., \& Kwak, W. J. (2015). Ethical leadership and followers' attitudes toward corporate social responsibility: The role of perceived ethical work climate. Social Behavior and Personality: an international journal, 43(3), 353-365.
Cosby, D. M. (2014). Sustainability program leadership for human resource development professionals: A competency model. Journal of Organizational Culture, Communications and Conflict, 18(2), 79.

Dentoni, D., Blok, V., Lans, T., \& Wesselink, R. (2012). Developing human capital for agrifood firms' multistakeholder interactions. International Food and Agribusiness Management Review, 15, 61-68.

Dentoni, D., Blok, V., Lans, T., \& Wesselink, R. (2012). Developing human capital for agrifood firms' multistakeholder interactions. International Food and Agribusiness Management Review, 15, 61-68.

Eisenhardt, K. M. (1989). Building theories from case study research. Academy of Management Review, 14(4), 532-550.

Egri, C. P., \& Herman, S. (2000). Leadership in the North American environmental sector: Values, leadership styles, and contexts of environmental leaders and their organizations. Academy of Management journal, 43(4), 571-604.

Gardner, W. L., Avolio, B. J., Luthans, F., May, D. R., \& Walumbwa, F. (2005). "Can you see the real me?": A self-based model of authentic leader and follower development. The Leadership Quarterly, 16(3), 343-372.

Hallinger, P., \& Suriyankietkaew, S. (2018). Science mapping of the knowledge base on sustainable leadership, 1990-2018. Sustainability, 10(12), 4846.

Hansen, S. D., Dunford, B. B., Alge, B. J., \& Jackson, C. L. (2016). Corporate social responsibility, ethical leadership, and trust propensity: A multi-experience model of perceived ethical climate. Journal of Business Ethics, 137(4), 649-662.

Heizmann, H., \& Liu, H. (2018). Becoming green, becoming leaders: Identity narratives in sustainability leadership development. Management Learning, 49(1), 40-58.

Hind, P., Wilson, A., \& Lenssen, G. (2009). Developing leaders for sustainable business. Corporate Governance: The international journal of business in society, 9(1), 7-20. 
Huang, S. K. (2013). The impact of CEO characteristics on corporate sustainable development. Corporate Social Responsibility and Environmental Management, 20(4), 234-244.

Índice de Sustentabilidade Empresarial. BMÆF Bovespa. Retrieved from http://www.isebvmf.com.br/index. php?r=site/conteudo\&id=1\#apresenta

Kemp, R. G. M., Nijhoff-Savvaki, R., Ruitenburg, R., Trienekens, J. H., \& Omta, S. W. F. (2014). Sustainabilityrelated innovation adoption: The case of the Dutch pig farmer. Journal on Chain and Network Science, 14(1), 69-78.

Ketola, T. (2010), Responsible leadership: Building blocks of individual, organizational and societal behavior. Corporate Social Responsibility and Environmental Management, 17(3) 173-184.

Koednok, S. (2011). Leadership strategy for human capital management in Asian economy towards global integration. International Conference on Economics, Business and Management, Singapore: Maldives.

Kramar, R. (2014). Beyond strategic human resource management: Is sustainable human resource management the next approach? The International Journal of Human Resource Management, 25(8), 1069-1089.

Kurucz, E.C., Colbert, B., Lüdeke-Freund, F., Upward, A. \& Willard, B. (2017). Relational leadership for strategic sustainability: Practices and capabilities to advance the design and assessment of sustainable business models. Journal of Cleaner Production, 140, 189-204.

Langley, A., \& Abdallah, C. (2011). Templates and turns in qualitative studies of strategy and management. Building methodological bridges: Research methods in strategy and management, 6, 201-235.

Lans, T., Blok, V., \& Wesselink, R. (2014). Learning apart and together: towards an integrated competence framework for sustainable entrepreneurship in higher education. Journal of Cleaner Production, 62, 37-47.

Lozano, R. (2015). A holistic perspective on corporate sustainability drivers. Corporate Social Responsibility Environmental Management, 22(1), 32-44.
Lucci, R. M.; Brunstein, J., \& Godoy, A. S. (2013). Competências Societais e Sustentabilidade segundo um grupo de gestores de uma Instituição Hospitalar Pública. In: XVI Seminários em Administração, Brazil: São Paulo.

Macke, J., \& Genari, D. (2019). Systematic literature review on sustainable human resource management. Journal of cleaner production, 208, 806-815.

Maon, F., Lindgreen, A., \& Swaen, V. (2009). Designing and implementing corporate social responsibility: An integrative framework grounded in theory and practice. Journal of Business Ethics, 87, 71-89.

McCann, J., \& Sweet, M. (2014). The perceptions of ethical and sustainable leadership. Journal of Business Ethics, 121(3), 373-383.

Minelgaite, I., Edvardsson, I. R., Stangej, O., \& Stankeviciene, J. (2019). Sustainable leader identity construction: A follower-centric approach. Transformations in Business \& Economics, 18(2), 47.

Nambiar, P., \& Chitty, N. (2014). Meaning making by managers: Corporate discourse on environment and sustainability in India. Journal of business ethics, 123(3), 493-511.

Osagie, E. R., Wesselink, R., Blok, V., Lans, T., \& Mulder, M. (2016). Individual competencies for corporate social responsibility: A literature and practice perspective. Journal of Business Ethics, 135(2), 233-252.

Paillé, P., Chen, Y., Boiral, O., \& Jin, J. (2014). The impact of human resource management on environmental performance: An employee-level study. Journal of Business Ethics, 121(3), 451-466.

Pettigrew, A. M. (1990). Longitudinal field research on change: Theory and practice. Organization Science, 1(3), 267-292.

Petrini, M., \& Pozzebon, M. (2010). Integrating sustainability into business practices: learning from Brazilian firms. $B A R$ Brazilian Administration Review, 7(4), 362-378.

Pozzebon M., Rodriguez, C.\& Petrini, M. (2014). Dialogical principles for qualitative inquiry: A nonfoundational path. International Journal of Qualitative Methods, 13(1), 293-317.

Ramirez, E. (2013). Consumer-defined sustainably oriented firms and factors influencing adoption. Journal of Business Research, 66(11), 2202-2209. 
Renwick, D. W., Redman, T., \& Maguire, S. (2013). Green human resource management: A review and research agenda. International Journal of Management Reviews, 15(1), 1-14.

Saha, A. (2014). Corporate Social Responsibility and Managerial Competencies: A Dynamic Requirement. In: European Conference on Management, Leadership \& Governance, Zagreb, Croatia.

Sharma, S. (2000). Managerial interpretations and organizational context as predictors of corporate choice of environmental strategy. Academy of Management journal, 43(4), 681-697.

Shrivastava, P. (1994). Ecocentric leadership in the 21st century. The Leadership Quarterly, 5(3-4), 223-226.

Todorov, M. D. C. A., Kniess, C. T., \& Martins, C. B. (2013). Competências de gerentes de projetos sustentáveis. Revista de Gestão e Projetos, 4(3), 98.

Voltolini, R. (2011). Conversas com líderes sustentáveis: $O$ que aprender com quem fez quem está fazendo a mudança para a sustentabilidade. São Paulo: SENAC.
Voltolini, R. (2012). Reflexôes sobre a liderança em sustentabilidade. Revista Brasileira de Administração Cientifica, 3(1), 83-93.

Waldman, D. A., \& Siegel, D. (2008). Defining the socially responsible leader. The Leadership Quarterly, 19(1), 117-131.

Wiek, A., Withycombe, L.,\& Redman, C. L. (2011). Key competencies in sustainability: A reference framework for academic program development. Sustainability science, 6(2), 203-218.

Williams, S., \& Turnbull, S. (2015). Developing the next generation of globally responsible leaders: Generation Y perspectives and the implications for green HRD. Advances in Developing Human Resources, 17(4), 504-521.

Wu, L. Z., Kwan, H. K., Yim, F. H. K., Chiu, R. K., \& He, X. (2015). CEO ethical leadership and corporate social responsibility: A moderated mediation model. Journal of Business Ethics, 130(4), 819-831.

Yin, R. K. (2005). Estudo de caso: Planejamento e métodos. Porto Alegre: Bookman. 


\section{Supporting Agencies:}

CAPES

\section{Authors:}

1. Ananda Borgert Armani, Master's Degree, PUCRS, Porto Alegre, Brazil.

E-mail: naniarmani@hotmail.com

ORCID

(D) 0000-0003-3015-0993

2. Maira Petrini, Post-Doctorate, PUCRS, Porto Alegre, Brazil.

E-mail: maira.petrini@pucrs.br

ORCID

(1) 0000-0002-3914-2589

3. Ana Clarissa Santos, Post-Doctorate, PUCRS, Porto Alegre, Brazil.

E-mail: ana.clarissa@pucrs.br

ORCID

(D) $0000-0002-7641-7983$

\section{Contribution of each author}

\begin{tabular}{lcc}
\hline \multicolumn{1}{c}{ Contribution } & Ananda Armani & Maira Petrini \\
\hline 1. Definition of research problem & $\sqrt{ }$ & $\sqrt{ }$ \\
2. Development of hypotheses or research questions (empirical studies) & $\sqrt{ }$ & $\sqrt{ }$ \\
3. Development of theoretical propositions (theoretical work) & $\sqrt{ }$ & $\sqrt{ }$ \\
4. Theoretical foundation/literature review & $\sqrt{ }$ & $\sqrt{ }$ \\
5. Definition of methodological procedures & $\sqrt{ }$ & $\sqrt{ }$ \\
6. Data collection & $\sqrt{ }$ & $\sqrt{ }$ \\
7. Statistical analysis & $\sqrt{ }$ \\
8. Analysis and interpretation of data & & $\sqrt{ }$ \\
9. Critical revision of the manuscript & $\sqrt{ }$ \\
10. Manuscript writing & & $\sqrt{ }$ \\
11. Other & & $\sqrt{ }$ \\
\hline
\end{tabular}

